\title{
Diet-Dependent Net Endogenous Acid Load of Vegan Diets in Relation to Food Groups and Bone Health-Related Nutrients: Results from the German Vegan Study
}

\author{
Alexander Ströhle ${ }^{a}$ Annika Waldmann ${ }^{b}$ Jochen Koschizke ${ }^{a}$ Claus Leitzmann ${ }^{c}$ \\ Andreas Hahn ${ }^{a}$ \\ a Nutrition Physiology and Human Nutrition Unit, Institute of Food Science and Human Nutrition, Leibniz University \\ of Hannover, Hannover, 'b Institute of Clinical Epidemiology, UKSH Campus Lübeck, Lübeck, and ' Institute of \\ Nutrition Science, Justus Liebig University Giessen, Giessen, Germany
}

\section{Key Words}

Acid load · Bone health · Estimated diet-dependent net acid load $\cdot$ Renal acid load $\cdot$ Vegan diets

\begin{abstract}
Background/Aims: Dietary composition has been shown to affect acid-base homeostasis and bone health in humans. We investigated the potential renal acid load (PRAL) and the estimated diet-dependent net acid load (net endogenous acid production, NEAP) in adult vegans and evaluated the relationships between NEAP, food groups and intake of bone health-related nutrients. Methods: The German Vegan Study (GVS) is a cross-sectional study. Data from healthy men ( $\mathrm{n}=$ 67) and women $(n=87)$, aged $21-75$ years, who fulfilled the study criteria (vegan diet for $\geq 1$ year prior to study start; age $\geq 18$ years, and no pregnancy/childbirth during the last 12 months) were included in the analysis. NEAP values were calculated from diet composition using two models: one based on the protein/potassium quotient and another taking into account an anthropometry-based loss of urinary organic anions. Results: Mean daily intakes of phosphorus, potassium, sodium, magnesium and vitamin C were above, and vitamin D and calcium below Dietary Reference Intake (DRI). Regardless of the model used, the diet in the GVS was characterized
\end{abstract}

by a nearly neutral NEAP. A strong correlation was observed between the NEAP values of the two models $\left(r_{s}=0.873, p<\right.$ 0.001). Only the consumption of fruits decreased constantly across the increasing quartiles of NEAP. Conclusions: It can be hypothesized that vegan diets do not affect acid-base homeostasis. With respect to bone health, the significance of this finding needs further investigation.

Copyright $\odot 2011$ S. Karger AG, Basel

\section{Introduction}

Since the beginning of the 20th century, when the physiologists Sherman and Gettler [1] as well as Blatherwick [2] published their experimental data, it is well known that dietary composition affects urine $\mathrm{pH}$ and acid-base homeostasis in man [3-5]. In the meantime, evidence indicates that even small diet-induced disturbances in acidbase homeostasis have pathogenic effects [6]. In particular, there is growing epidemiological evidence showing negative associations between the diet-dependent net acid load (net endogenous acid production, NEAP) and bone health [7-10]. Furthermore, in vitro studies have shown that even a small decrease in $\mathrm{pH}$ resulted in a remarkable increase in bone resorption as a result of osteoclast stimulation [11-

\section{KARGER}

Fax +4161306 1234 E-Mail karger@karger.ch www.karger.com
(C) 2011 S. Karger AG, Basel

0250-6807/11/0594-0117\$38.00/0

Accessible online at:

www.karger.com/anm
Dr. Alexander Ströhle

Nutrition Physiology and Human Nutrition Unit

Institute of Food Science and Human Nutrition, Leibniz University of Hannover

Am Kleinen Felde 30, DE-30167 Hannover (Germany)

Tel. +49511762 5093, E-Mail stroehle@ nutrition.uni-hannover.de 
13]. Additionally, net acid-producing diets increase urinary calcium excretion in a dose-dependent manner [14]. Accordingly, it has been hypothesized that net acid-producing diets will induce osteoporosis in the long run [15]. Consequently, alkaline supplements decrease bone absorption in humans [16-18].

In this context, benefits of plant-based diets on bone health have received particular attention since fruits, vegetables, tubers and roots are net base-producing foods [4]. Indeed, diets rich in fruits and vegetables have a positive effect on the calcium economy and markers of bone metabolism in both males and females [15]. Because vegetarians and especially vegans tend to consume more minimally processed plant foods like fresh fruits and vegetables $[19,20]$, it seems plausible that such diets are characterized by a net base load and hence are of particular benefit to the bones. However, the interpretation of the effect of vegan diets on acid-base homeostasis and bone metabolism merits further consideration in light of the fact that vegans also generally consume high amounts of cereal grains [20,21], which are net acid producers [4]. Until now, the question of whether a vegetarian or a vegan diet has any positive or negative effect on bone health is a contentious issue $[22,23]$.

Although a large number of studies on vegetarian [24$35]$ and vegan nutrition [20, 21, 36-41] have been published during the last years, only one small study has examined the effect of vegan diets on acid-base homeostasis [42]. Whereas the effect of diets on human acid-base status has significant implications on skeletal health [7-10, $43,44]$, the primary aim of this cross-sectional study was to investigate how vegan diets affect acid-base balance. Furthermore, we evaluated the associations between NEAP, food groups and the intake of bone health-related nutrients in 154 apparently healthy adult vegans.

\section{Methods}

\section{Ethical Considerations}

The German Vegan Study (GVS) was conducted in accordance with the Helsinki Declaration of 1964 as amended in 1996. Since there was no intervention, the Ethics Commission of the State of Lower Saxony decided that an ethical approval was not required. All subjects participated voluntarily, gave written consent prior to participation and were free to withdraw from the study at any time.

\section{Recruitment and Screening of Subjects}

Participants were recruited by advertisements in eight German magazines. Of initially 868 potential participants, a total of 154 persons took part in all study segments [pre-/main questionnaire and food frequency questionnaire (FFQ)] and fulfilled the follow- ing study criteria: vegan diet for $\geq 1$ year prior to the start of the study; age $\geq 18$ years; resident in Germany, and no pregnancy or childbirth during the last 12 months. Exclusion criteria were: severe illness during the last 12 months (such as malignant or cardiovascular diseases, renal failure, or severe diseases of the gastrointestinal tract), diagnosis of a blood coagulation disorder, treatment with inhibitors of blood coagulation, alcohol and/or drug abuse, participation in another study during the last month and stating the ingestion of fish or meat in any of the study questionnaires.

Life course factors (except alcohol consumption; FFQ) were evaluated by means of the main questionnaire of the study, in which frequency, duration and kind of physical activity as well as amount of smoking (number of cigarettes per day) were assessed. During the (physical) examinations, the participants were screened for health status by a general practitioner [standardized questionnaire with questions regarding (severe) diseases and (minor) complications] in order to identify any of the exclusion criteria. Body height and weight were determined by trained personnel. Body weight was measured without shoes and with light clothes on using a calibrated SECA scale and recorded to the nearest $0.1 \mathrm{~kg}$, and body height was determined without shoes using a tape measure and recorded to the nearest centimeter. Body mass index (BMI) was calculated from body weight (in $\mathrm{kg}$ ) divided by height squared (in $\mathrm{m}^{2}$ ).

\section{Definition of 'Vegan'}

As previously described [20], persons were included in the study when they were adhering to either a strict vegan diet (SV, $\mathrm{n}=98)$ or a near-vegan diet [moderate vegan diet $(\mathrm{MV}, \mathrm{n}=56)$ ]. In $\mathrm{MV}$ diets, a maximum of $5 \%$ of the ingested food energy came from eggs, milk and/or dairy products. Regarding 'moderate vegans', it was discussed that on the one hand, the consumed amounts of eggs ( $0.88 \pm 3.31 \mathrm{~g} /$ day), milk and dairy products $(7.95 \pm 10.1$ $\mathrm{g} /$ day) in the MV subgroup were so low that it seemed not appropriate to call them restricted lacto-ovo-vegetarians. On the other hand, the consumption of eggs, milk and dairy products makes it difficult - if not impossible - to call those persons (strict) vegans. Therefore, we decided to call them moderate vegans rather than restricted lacto-ovo-vegetarians or strict vegans.

\section{Collection of Dietary Data}

A slight modification of the validated FFQ used in the Giessen Raw-Food Study [45] was used in the GVS for data collection. The original FFQ was complemented for vegan foods; foods of animal origin - except eggs, butter, milk and dairy products - were excluded. The GVS-FFQ included 199 vegan foods and 7 non-vegan foods such as dairy products and eggs. In the GVS-FFQ, common household measures and their equivalents in grams or milliliters were given for each food item. In some cases, portion sizes were made clear with photos or specific comments (i.e. 9 strawberries of a size of walnuts weigh $150 \mathrm{~g}$; an orange of the size of a tennis ball equals $250 \mathrm{~g}$ ). In addition, participants were asked for copies of recipes of homemade vegan dishes.

In order to minimize seasonal differences, the FFQ was administered twice: once in autumn and once in spring. In each of the two FFQ, food consumption was documented over a period of 9 consecutive days. However, the first 2 days of each 9-day FFQ were regarded as a training phase and excluded from the analyses; only the following 7 days were evaluated. On the basis of the German nutrient data base (BLS II.2), we developed our own software (Par- 
adox database) to calculate the amounts of nutrients ingested. Missing nutritional information on vegan food and dishes was added to the database either based on the recipes provided by the participants or it was requested from the food manufacturers. Finally, 245 food items (including 18 beverages) were listed in the database.

\section{Computing the Estimated NEAP and the Potential Renal Acid} Load

Since direct measurement of acid-base balance via 24-hour urine collection is not practical in larger epidemiological studies, several algorithms for estimating the daily NEAP from the food composition have been developed [46]. Frassetto et al. [3], for example, estimated NEAP from the protein/potassium ratio of the diet. In contrast, Remer and Manz [4] as well as Remer et al. [47] calculated NEAP from average intestinal absorption rates of ingested proteins and minerals as well as an anthropometry-based estimate for organic acid excretion. Based on the fact that each of the algorithms has its merits and drawbacks [46], we applied both models and examined how they alter NEAP (in $\mathrm{mEq} /$ day) in vegan diets.

The algorithm formulas for the calculations of the two models are given in the following:

$$
\mathrm{NEAP}_{\text {Frassetto }}=54.5 \cdot \text { protein } / \text { potassium }-10.2
$$

This algorithm considers the diet contents of protein (an acid precursor; in g/day) and potassium (an index of base precursors; in $\mathrm{mEq} /$ day) from organic anions [3].

$$
\mathrm{NEAP}_{\text {Remer-Manz }}=\mathrm{PRAL}+\mathrm{OA}_{\mathrm{est}}
$$

where PRAL (in $\mathrm{mEq} /$ day) denotes the dietary potential renal acid load and $\mathrm{OA}_{\text {est }}$ (in $\mathrm{mEq}$ /day) represents anthropometry-based estimated urinary organic anions.

PRAL was calculated as follows [4, 47]:

PRAL $=0.49 \cdot$ protein $+0.037 \cdot$ phosphorus -

$0.021 \cdot$ potassium $-0.026 \cdot$ magnesium

with protein given in $\mathrm{g} /$ day and phosphorus, potassium and magnesium in mg/day. Divergent from the original model of Remer and Manz [4], but in accordance with Alexy et al. [48], calcium was not included in the PRAL algorithm because its absorption is highly variable.

The computation of $\mathrm{OA}_{\text {est }}$ (in $\mathrm{mEq} /$ day) was carried out using the following formula [49]:

$$
\mathrm{OA}_{\text {est }}=0.007184 \cdot \text { height }^{0.725} \cdot \text { weight }^{0.425} \cdot 41 / 1.73
$$

with height given in $\mathrm{cm}$ and weight in $\mathrm{kg}$.

\section{Classification of Food Groups}

Referring to Alexy et al. [48] and Gannon et al. [50], several food groups were formed and classified:

- fruits: fresh fruits and fruit products (frozen, dried and canned fruits);

- vegetables: fresh, frozen and canned vegetables;

- cereals and staple foods: rice, wheat, rye, millet, oat and oatmeal, pasta, breakfast cereals and cereal bars;

- bread and pastries: white and wholemeal bread, soft grain, rolls and other bread products;

- potatoes: boiled, mashed, fried/roasted potatoes, potato salads and dishes;

Diet-Dependent Net Endogenous Acid Load of Vegan Diets
- legumes: beans, lentils and soy products;

- nuts and seeds: hazelnuts, walnuts, cashew nuts, almonds, and sunflower and pumpkin seeds;

- milk and dairy products: whole, semi-skimmed and skimmed milk; yoghurts, and other fermented milk products;

- cheese: curd, fresh and cottage cheese, and hard and soft cheese;

- eggs: eggs and egg dishes;

- coffee: instant, coffee bean and decaffeinated preparations, and

- tea and herbal tea: infusions, instant and decaffeinated preparations.

\section{Statistical Methods}

Statistical analysis was performed using SPSS 17.0 (SPSS, Chicago, Ill., USA). Results are shown as means \pm SD or as medians with 25 th and 75 th percentiles (interquartile range). The following two-tailed tests at the $5 \%$ level of significance were employed to evaluate the data: to analyze differences in skewed data between two subgroups (SV and MV; sex), the Mann-Whitney U test was used. For normal distributions, the independent sample t test was chosen. Normal data distribution was checked visually and using the Kolmogorov-Smirnov test. Dealing with nominal data, the $\chi^{2}$ test was employed to evaluate significant differences. Differences in nutrient intakes as well as intake of different food groups between persons within the lowest and the highest NEAP per MJ quartiles were tested with the Mann-Whitney U test.

Associations between $\mathrm{NEAP}_{\text {Frassetto }}$ and NEAP $\mathrm{Remer-Manz}_{\text {, }}$ NEAP values and energy-adjusted nutrients were examined using the Spearman rank correlation.

\section{Results}

\section{Subject Characteristics}

Of the subjects recruited, 56.5\% were females (SV: 51.0\% and MV: 66.1\%; $\mathrm{p}=0.07$ ). The two subgroups (SV and MV) did not differ in mean age (SV: $43.4 \pm 15.4$ years and MV: $45.7 \pm 14.2$ years; $\mathrm{p}=0.358$ ) and their mean BMI (SV: $21.3 \pm 2.73$ and MV: $21.3 \pm 2.20$; for anthropometric details of the whole study population see Waldmann et al. [20]).

\section{Food and Nutrient Intakes and Bone-Related Nutrient Interrelationships}

Due to subgroup definition, strict and moderate vegans differed significantly in their egg, milk and dairy product consumption $(\mathrm{p}<0.001)$. Intake of legumes, especially soy and soy products, was higher in strict vegans (SV: $102 \pm 99.1 \mathrm{~g} /$ day and MV: $56.8 \pm 85.4 \mathrm{~g} /$ day; $\mathrm{p}<$ $0.001)$. The daily intakes of total energy, macronutrients and bone-related micronutrients of the two vegan subgroups are shown in table 1 . Mean daily intakes of vitamin $\mathrm{C}$, phosphorus, magnesium, sodium and potassium were above Dietary Reference Intake (DRI) recommen- 
Table 1. Dietary intakes (total energy intake, macronutrients and bone-related micronutrients) of strict and moderate vegans within the GVS (means \pm SD)

\begin{tabular}{|c|c|c|c|c|c|}
\hline & $\mathrm{DRI}^{\mathrm{a}}$ & $\begin{array}{l}\text { All vegans } \\
(\mathrm{SV} \text { and } \mathrm{MV} ; \mathrm{n}=154)\end{array}$ & $\begin{array}{l}\text { Strict vegans } \\
(\mathrm{n}=98)\end{array}$ & $\begin{array}{l}\text { Moderate vegans } \\
(\mathrm{n}=56)\end{array}$ & $\begin{array}{l}\mathrm{p} \\
\text { value }^{\mathrm{b}}\end{array}$ \\
\hline Energy intake, MJ/day & $\begin{array}{l}9.5 \text { (females) } \\
12 \text { (males) }\end{array}$ & $8.23 \pm 2.77$ & $8.59 \pm 2.97$ & $7.60 \pm 2.28$ & 0.033 \\
\hline Carbohydrates, \% of energy & $>50$ & $57.1 \pm 7.48$ & $56.4 \pm 7.74$ & $58.2 \pm 6.94$ & 0.146 \\
\hline Protein, $\%$ of energy & $9-11$ & $11.6 \pm 2.07$ & $11.9 \pm 2.11$ & $11.0 \pm 1.90$ & 0.013 \\
\hline Protein, g/kg body weight & 0.8 & $0.89 \pm 0.32$ & $0.94 \pm 0.34$ & $0.81 \pm 0.27$ & 0.012 \\
\hline Fat, $\%$ of energy & 30 & $29.7 \pm 7.82$ & $30.3 \pm 8.22$ & $28.8 \pm 7.02$ & 0.255 \\
\hline Vitamin $\mathrm{C}, \mathrm{mg} /$ day & 100 & $324.4 \pm 194.3$ & $312.9 \pm 200.8$ & $344.6 \pm 182.4$ & 0.331 \\
\hline Vitamin C, mg/MJ & $\begin{array}{l}13 \text { (females) } \\
10 \text { (males) }\end{array}$ & $40.2 \pm 20.6$ & $36.3 \pm 18.6$ & $46.9 \pm 22.5$ & 0.002 \\
\hline Vitamin $\mathrm{D}, \mu \mathrm{g} /$ day & 5 & $0.65 \pm 0.64$ & $0.64 \pm 0.64$ & $0.67 \pm 0.64$ & 0.439 \\
\hline Vitamin $\mathrm{D}, \mu \mathrm{g} / \mathrm{MJ}$ & $\begin{array}{l}0.6 \text { (females) } \\
0.5 \text { (males) }\end{array}$ & $0.08 \pm 0.07$ & $0.07 \pm 0.07$ & $0.09 \pm 0.08$ & 0.152 \\
\hline Phosphorus, mg/day & 700 & $1,343.2 \pm 471.9$ & $1,422.1 \pm 493.3$ & $1,205.1 \pm 399.8$ & 0.006 \\
\hline Phosphorus, mg/MJ & not stated & $164.7 \pm 29.3$ & $167.9 \pm 29.8$ & $159.1 \pm 27.7$ & 0.072 \\
\hline Magnesium, mg/day & $\begin{array}{l}300 \text { (females) } \\
350 \text { (males) }\end{array}$ & $618.4 \pm 197.5$ & $644.2 \pm 205.5$ & $573.2 \pm 175.4$ & 0.032 \\
\hline Magnesium, mg/MJ & $\begin{array}{l}38 \text { (females) } \\
34 \text { (males) }\end{array}$ & $76.6 \pm 13.3$ & $76.8 \pm 13.6$ & $76.3 \pm 13.1$ & 0.826 \\
\hline Calcium, mg/day & 1,000 & $839.8 \pm 296.1$ & $851.4 \pm 305$ & $819.4 \pm 281.5$ & 0.521 \\
\hline Calcium, mg/MJ & $\begin{array}{l}128 \text { (females) } \\
98 \text { (males) }\end{array}$ & $106.0 \pm 32.7$ & $102.9 \pm 30.6$ & $111.4 \pm 35.7$ & 0.121 \\
\hline Potassium, g/day & 2 & $4.88 \pm 1.68$ & $4.95 \pm 1.78$ & $4.78 \pm 1.51$ & 0.550 \\
\hline Potassium, g/MJ & not stated & $0.60 \pm 0.13$ & $0.58 \pm 0.12$ & $0.64 \pm 0.13$ & 0.008 \\
\hline Sodium, g/day & 0.55 & $2.01 \pm 1.01$ & $2.16 \pm 1.03$ & $1.75 \pm 0.91$ & 0.013 \\
\hline Sodium, g/MJ & not stated & $0.26 \pm 0.12$ & $0.26 \pm 0.13$ & $0.23 \pm 0.10$ & 0.061 \\
\hline
\end{tabular}

${ }^{a}$ According to the German Nutrition Society [51]; age group 25-51 years; DRI values apply to both females and males, unless stated otherwise.

${ }^{\mathrm{b}}$ All statistical tests were conducted with the t test for unpaired samples (exception: Mann-Whitney U test for vitamin D, in $\mu \mathrm{g} / \mathrm{day}$ ).

dations, while intakes of vitamin D and calcium were below DRI [51]. There were significant differences regarding intakes of protein, phosphorus, magnesium, and sodium between SV and MV groups, with lower consumption in the MV group. Data on nutrient density for micronutrient intake are also shown in table 1. Table 2 lists high and significantly positive correlations $\left(r_{s} \geq 0.6\right)$ between magnesium and calcium, magnesium and phosphorus, vitamin $\mathrm{C}$ and potassium, protein and phosphorus as well as protein and sodium.

\section{Estimates of the Diet-Dependent Net Endogenous Acid Load}

Besides anthropometric data and PRAL, table 3 shows the findings of the computed NEAP in the GVS with respect to the two different algorithms established by Remer and Manz [4] as well as Frassetto et al. [3]. Regardless of the model used, both the entire vegan cohort and the two subgroups (SV and MV) were characterized by nearly neutral NEAP values. However, NEAP differed significantly between the dietary subgroups. In the total cohort, women had lower NEAP values (median: $15.1 \mathrm{mEq} /$ day) than men (median: $16.7 \mathrm{mEq} /$ day), but the difference was only significant for $\mathrm{NEAP}_{\text {Frassetto }}(\mathrm{p}=0.008)$.

\section{Comparison of the Two NEAP Algorithms}

As shown in figure 1, the NEAP values calculated with the different methods were significantly correlated $(\mathrm{r}=$ $0.873, \mathrm{p}<0.001)$. However, the modified formula of Remer and Manz [4] revealed a greater range and lower NEAP values (median: 7.26 , range: -113 to 48.3 ) than the formula of Frassetto et al. [3] (median: 15.6, range: -0.08 to 33.8).

Association between Specific Food Groups and NEAP

Table 4 displays a comparison of the median values for specific food groups categorized according to NEAP 
Table 2. Spearman's rank correlation between bone-related nutrient intakes (versus the total energy consumed)

\begin{tabular}{|c|c|c|c|c|c|c|c|c|}
\hline & & Phosphorus & Magnesium & Potassium & Sodium & Vitamin C & Vitamin D & Protein \\
\hline \multirow[t]{2}{*}{ Calcium } & $\mathrm{r}_{\mathrm{s}}$ & 0.087 & 0.621 & 0.377 & 0.028 & 0.379 & -0.018 & 0.116 \\
\hline & $\mathrm{p}$ & 0.283 & $<0.001$ & $<0.001$ & 0.735 & $<0.001$ & 0.826 & 0.153 \\
\hline \multirow[t]{2}{*}{ Phosphorus } & $r_{s}$ & 1.000 & 0.600 & -0.231 & 0.465 & -0.424 & -0.173 & 0.774 \\
\hline & $\mathrm{p}$ & & $<0.001$ & 0.004 & $<0.001$ & $<0.001$ & 0.032 & $<0.001$ \\
\hline \multirow[t]{2}{*}{ Magnesium } & $r_{s}$ & & 1.000 & 0.211 & 0.223 & 0.029 & -0.317 & 0.447 \\
\hline & $\mathrm{p}$ & & & 0.009 & 0.005 & 0.719 & $<0.001$ & $<0.001$ \\
\hline \multirow[t]{2}{*}{ Potassium } & $\mathrm{r}_{\mathrm{s}}$ & & & 1.000 & -0.301 & 0.817 & -0.080 & -0.295 \\
\hline & $\mathrm{p}$ & & & & $<0.001$ & $<0.001$ & 0.323 & $<0.001$ \\
\hline \multirow[t]{2}{*}{ Sodium } & $\mathrm{r}_{\mathrm{s}}$ & & & & 1.000 & -0.447 & -0.077 & 0.634 \\
\hline & $\mathrm{p}$ & & & & & $<0.001$ & 0.344 & $<0.001$ \\
\hline \multirow[t]{2}{*}{ Vitamin C } & $r_{s}$ & & & & & 1.000 & -0.029 & -0.462 \\
\hline & $\mathrm{p}$ & & & & & & 0.723 & $<0.001$ \\
\hline \multirow[t]{2}{*}{ Vitamin D } & $\mathrm{r}_{\mathrm{s}}$ & & & & & & 1.000 & -0.187 \\
\hline & $\mathrm{p}$ & & & & & & & 0.020 \\
\hline
\end{tabular}

$\mathrm{r}_{\mathrm{s}}=$ Spearman's rank correlation coefficient $(\rho)$.

Table 3. Weight, height, BMI, OA est PRAL, and NEAP measures in the GVS (means \pm SD)

\begin{tabular}{|c|c|c|c|c|}
\hline & $\begin{array}{l}\text { All vegans } \\
(\mathrm{SV} \text { and } \mathrm{MV} ; \mathrm{n}=154)\end{array}$ & $\begin{array}{l}\text { Strict vegans } \\
(\mathrm{n}=98)\end{array}$ & $\begin{array}{l}\text { Moderate vegans } \\
(\mathrm{n}=56)\end{array}$ & $\mathrm{p}$ value $^{\mathrm{a}}$ \\
\hline Height, $\mathrm{cm}$ & $171 \pm 9.56$ & $172 \pm 9.71$ & $169 \pm 9.15$ & 0.110 \\
\hline Weight, kg & $62.6 \pm 10.8$ & $63.5 \pm 12.0$ & $61.0 \pm 7.99$ & 0.132 \\
\hline BMI & $21.3 \pm 2.54$ & $21.3 \pm 2.73$ & $21.3 \pm 2.20$ & 0.861 \\
\hline $\mathrm{OA}_{\mathrm{est}}, \mathrm{mEq} /$ day & $41.0 \pm 4.36$ & $41.4 \pm 4.76$ & $40.3 \pm 3.47$ & 0.109 \\
\hline PRAL, mEq/day & $-41.7 \pm 29.3$ & $-39.0 \pm 29.0$ & $-46.5 \pm 29.6$ & 0.037 \\
\hline Median & -32.9 & -28.8 & -44.2 & \\
\hline $\mathrm{NEAP}_{\text {Remer-Manz }}, \mathrm{mEq} /$ day & $-0.72 \pm 29.8$ & $2.41 \pm 29.3$ & $-6.19 \pm 30.1$ & 0.026 \\
\hline Median & 7.26 & 9.34 & -4.10 & \\
\hline $\mathrm{NEAP}_{\text {Frassetto }}, \mathrm{mEq} /$ day & $15.0 \pm 7.20$ & $16.3 \pm 6.73$ & $12.6 \pm 7.46$ & 0.002 \\
\hline Median & 15.6 & 17.4 & 12.1 & \\
\hline
\end{tabular}

${ }^{a}$ All statistical tests were conducted using the $t$ test for unpaired samples, except for PRAL and NEAP Remer-Manz $($ Mann-Whitney U test).

quartiles. Across the quartile of NEAP $\mathrm{Remer-Manz}_{\text {, only the }}$ median intake of fruits decreased significantly and above all constantly. Opposed to this, there was no clear and consistent association between the intake of cereals and staple foods, potatoes, nuts, seeds and legumes across the increasing NEAP quartiles.

\section{Association and Correlation of Macro- and}

Micronutrient Intake and Dietary Acidity

The median values of macro- and bone-related micronutrients across the quartiles of NEAP are given in ta- ble 5. Protein, phosphorus and sodium intake increased significantly, while intake of vitamin $\mathrm{C}$ and potassium decreased significantly across the increasing quartiles of NEAP.

Table 6 shows Spearman rank correlation coefficients between energy-adjusted nutrient intakes (nutrient intake per MJ) and NEAP according to Remer and Manz in the total GVS cohort. NEAP was positively associated with phosphorus, sodium and protein intake, but negatively associated with calcium, potassium and vitamin C intake. 
Table 4. Daily intake of food groups (g/day) across the quartiles of dietary-dependent net endogenous load (NEAPa) in the total study group

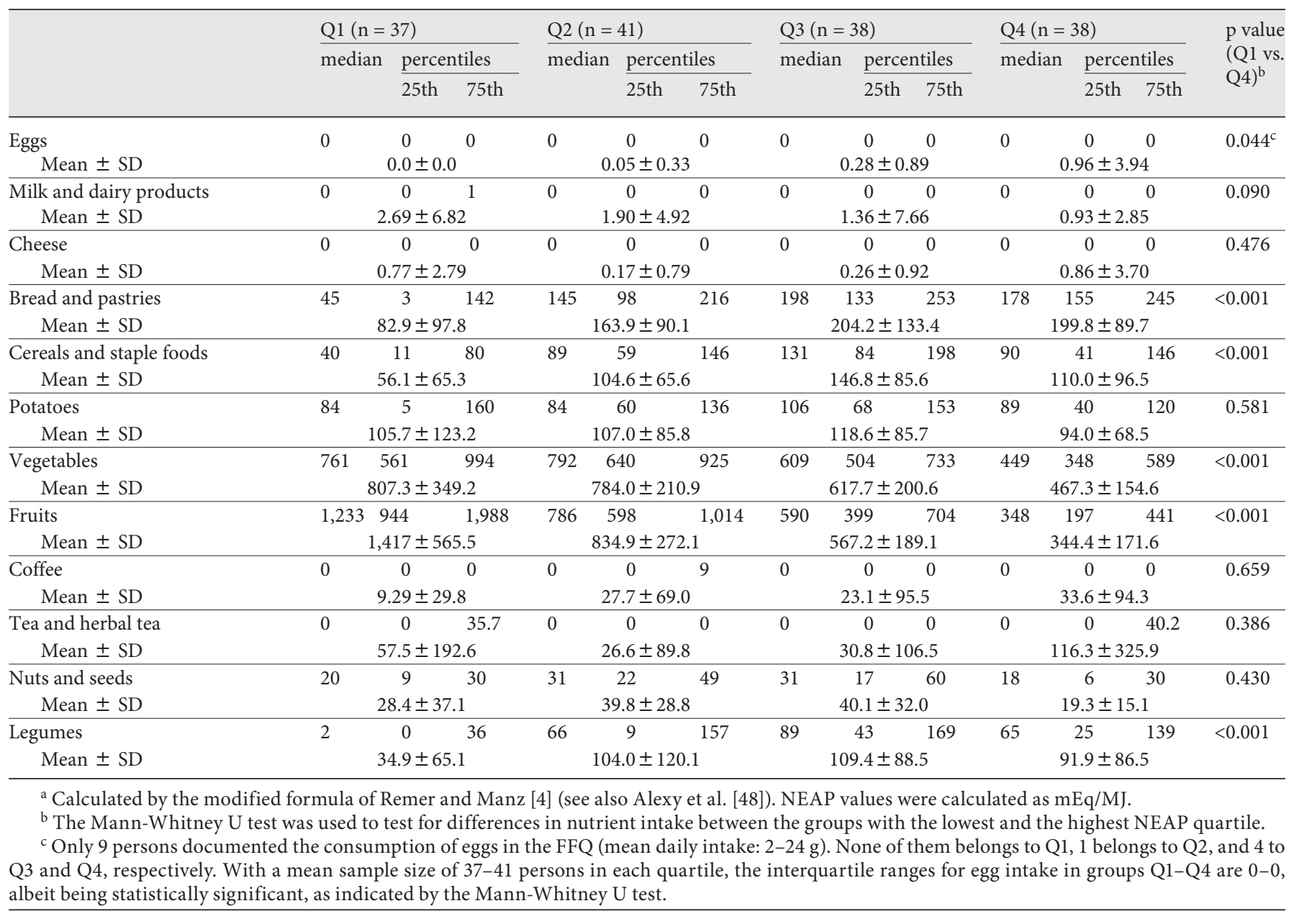

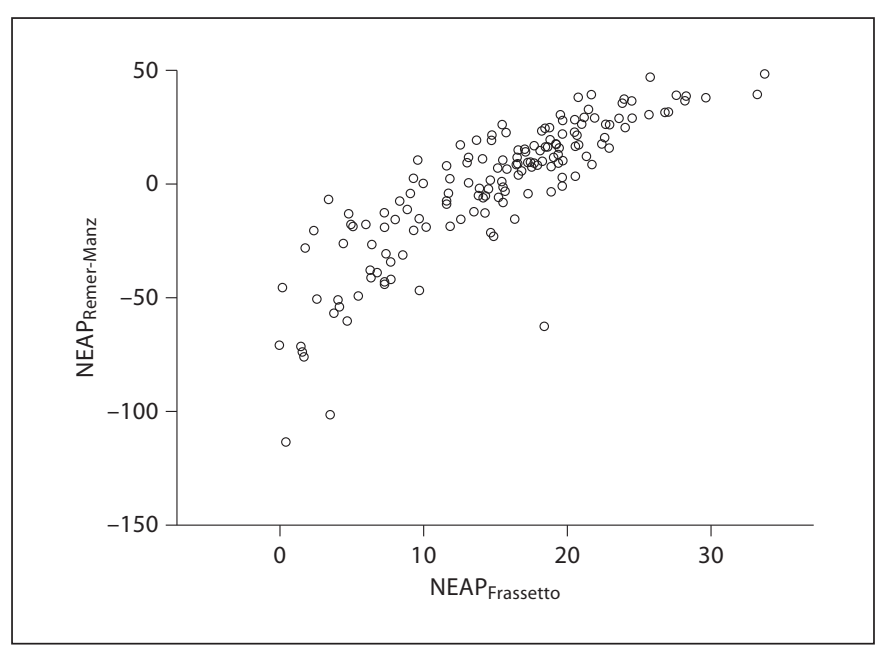

Fig. 1. Comparison of the two estimates of acid-base balance in vegan diets (SV and MV combined; $\mathrm{r}=0.873, \mathrm{p}<0.001$ ).

\section{Discussion}

The role of nutrition in human acid-base homeostasis has been a subject of controversy for a long time. Actually, because of the high capacity of the kidney to excrete acid prevents any serious diet-induced alterations in blood $\mathrm{pH}$, the pathophysiological relevance of the socalled low-grade metabolic acidosis in healthy adults has long been ignored [52]. However, currently, there is an increasing body of evidence from observational [7-10], clinical [16-18] and mechanistic studies [11,12] suggesting that even small diet-induced acid-base disturbances result in negative effects on bone health. Based on this background, the primary aim of the present analysis was to answer the following questions: Which NEAP is characteristic for vegan diets? Are the NEAP values obtained using the two NEAP algorithms from Remer and Manz 
Table 5. Daily intake of macro- and bone-related micronutrients across the quartiles of dietary-dependent net endogenous load $\left(\mathrm{NEAP}^{\mathrm{a}}\right)$ in the total study group

\begin{tabular}{|c|c|c|c|c|c|c|c|c|c|c|c|c|c|}
\hline & \multicolumn{3}{|c|}{$\mathrm{Q} 1(\mathrm{n}=37)$} & \multicolumn{3}{|c|}{$\mathrm{Q} 2(\mathrm{n}=41)$} & \multicolumn{3}{|c|}{ Q3 ( $\mathrm{n}=38)$} & \multicolumn{3}{|c|}{$\mathrm{Q} 4(\mathrm{n}=38)$} & \multirow{3}{*}{$\begin{array}{l}\mathrm{p} \\
\text { (Q1 } \\
\text { vs. } \\
\mathrm{Q} 4)^{\mathrm{b}}\end{array}$} \\
\hline & \multirow[t]{2}{*}{ median } & \multicolumn{2}{|c|}{ percentiles } & \multirow[t]{2}{*}{ median } & \multicolumn{2}{|c|}{ percentiles } & \multirow[t]{2}{*}{ median } & \multicolumn{2}{|c|}{ percentiles } & \multirow[t]{2}{*}{ median } & \multicolumn{2}{|c|}{ percentiles } & \\
\hline & & 25 th & 75th & & 25 th & 75th & & 25 th & 75th & & 25th & 75th & \\
\hline Energy, MJ/day & 8.8 & 6.5 & 10.1 & 8.7 & 6.9 & 10.9 & 7.9 & 6.9 & 10.1 & 6.6 & 5.0 & 7.9 & 0.001 \\
\hline Protein, En\% & 9 & 8 & 10 & 12 & 11 & 13 & 12 & 12 & 14 & 13 & 12 & 14 & $<0.001$ \\
\hline Fat, En\% & 29 & 24 & 37 & 31 & 25 & 35 & 29 & 25 & 33 & 29 & 24 & 31 & 0.229 \\
\hline Carbohydrates, En\% & 59 & 51 & 64 & 55 & 51 & 60 & 58 & 55 & 60 & 58 & 55 & 63 & 0.924 \\
\hline Vitamin C, mg/day & 487 & 391 & 669 & 367 & 293 & 422 & 235 & 195 & 279 & 156 & 116 & 199 & $<0.001$ \\
\hline Vitamin C, mg/MJ & 57.2 & 50.1 & 74.9 & 41.1 & 32.3 & 55.6 & 26.7 & 21.6 & 34.3 & 24.0 & 18.1 & 27.8 & $<0.001$ \\
\hline Phosphorus, g/day & 1.1 & 9.3 & 1.4 & 1.5 & 1.1 & 1.8 & 1.5 & 1.1 & 1.9 & 1.2 & 0.9 & 1.4 & 0.560 \\
\hline Phosphorus, mg/MJ & 136.5 & 110.9 & 145.5 & 169.7 & 149.0 & 183.3 & 176.4 & 164.9 & 197.4 & 182.3 & 163.8 & 198.3 & $<0.001$ \\
\hline Magnesium, mg/day & 571 & 491 & 721 & 683 & 521 & 808 & 632 & 548 & 751 & 481 & 382 & 608 & 0.003 \\
\hline Magnesium, mg/MJ & 69.7 & 64.9 & 78.3 & 75.2 & 66.5 & 89.0 & 79.3 & 70.9 & 88.4 & 74.5 & 66.4 & 83.8 & 0.294 \\
\hline Calcium, mg/day & 854 & 761 & 1,036 & 872 & 703 & 1,092 & 803 & 658 & 958 & 670 & 493 & 830 & $<0.001$ \\
\hline Calcium, mg/MJ & 104.7 & 93.5 & 127.0 & 98.3 & 86.2 & 119.2 & 94.3 & 79.5 & 117.7 & 101.1 & 79.8 & 124.5 & 0.270 \\
\hline Potassium, g/day & 6.4 & 4.8 & 7.3 & 5.5 & 4.2 & 6.1 & 4.4 & 3.9 & 5.1 & 3.4 & 2.7 & 3.8 & $<0.001$ \\
\hline Potassium, g/MJ & 0.74 & 0.65 & 0.82 & 0.61 & 0.55 & 0.66 & 0.55 & 0.49 & 0.59 & 0.50 & 0.46 & 0.57 & $<0.001$ \\
\hline Sodium, g/day & 1.3 & 0.6 & 1.8 & 2.2 & 1.4 & 3.1 & 2.3 & 1.7 & 2.9 & 1.9 & 1.4 & 2.6 & $<0.001$ \\
\hline Sodium, g/MJ & 0.14 & 0.07 & 0.22 & 0.26 & 0.17 & 0.31 & 0.29 & 0.21 & 0.33 & 0.32 & 0.25 & 0.36 & $<0.001$ \\
\hline
\end{tabular}

En $\%=\%$ of energy.

${ }^{a}$ Calculated by the modified formula of Remer and Manz [4] (see also Alexy et al. [48]). NEAP values were calculated as mEq/MJ.

${ }^{\mathrm{b}}$ Mann-Whitney U test was used to test for differences in nutrient intakes between the groups with the lowest and the highest NEAP quartile.

Table 6. Spearman's rank correlation between energy-adjusted bone-related nutrient intakes and NEAP values

\begin{tabular}{lccccccccc}
\hline & & Calcium & Phosphorus & Potassium & Sodium & Magnesium & Vitamin C & Vitamin D & Protein \\
\hline NEAP Remer-Manz & $\mathrm{r}_{\mathrm{s}}$ & -0.182 & 0.568 & -0.792 & 0.506 & 0.070 & -0.087 & 0.011 \\
& $\mathrm{p}$ & 0.024 & $<0.001$ & $<0.001$ & $<0.001$ & 0.387 & $<0.001$ & 0.890 & $<0.001$ \\
\hline
\end{tabular}

[4] and Frassetto et al. [3] related? Do bone health-related nutrients and specific food groups affect NEAP and how? Since an interpretation of bone-related effects on NEAP should be made in the context of the total diet [43], our secondary aims were to analyze bone health-associated nutrient intake and interrelationships among nutrients. In the following, those topics are discussed.

\section{NEAP of Vegan Diets}

In the present paper, NEAP of a larger vegan cohort was calculated for the first time. A comparison of the NEAP values computed with the two different methods showed that they were highly correlated $\left(r_{s}=0.873\right)$. This result is in accordance with findings from earlier studies. For example, Prynne et al. [43] and Gannon et al. [50] calculated for both methods a correlation coefficient of $r=0.76$ and $r=0.72$, respectively. Given the fact that the formula of Remer and Manz [4] seems to have a higher capacity to predict renal acid excretion [47], the results generated with the NEAP $\mathrm{P}_{\text {Remer-Manz }}$ algorithm should reflect a more realistic situation than the results obtained with the NEAP $\mathrm{P}_{\text {Frassetto }}$ method. Therefore, it seems plausible that vegans consume a more alkaline diet than calculated with the NEAP Frassetto method. However, from a physiological point of view, the differences in the NEAP values calculated with the two methods are apparently not relevant. Actually, regardless of the model used, vegan diets are characterized by virtually neutral NEAP values. This observation is in accordance with the findings of a small cross-sectional study ( $\mathrm{n}=10$ vegans) indicating 
a NEAP of $17.3 \pm 14.5 \mathrm{mEq} /$ day for a vegan diet [42]. In contrast, most modern, omnivore, Western diets show net acid-producing effects in the range of $>50 \mathrm{mEq} /$ day $[43,50,53,54]$. With respect to preventive medicine, the near neutral characteristic of the vegan diet is of interest, since it is known that neutral or net base-producing diets have shown multiple health benefits, e.g. decreased urinary calcium excretion and bone resorption [14, 16-18]. Because vegans tend to consume lower amounts of calcium, lower intake of that bone-related nutrient may be compensated by the 'calcium-saving effects' of the neutral character of vegan diets. This phenomenon would at least partly explain why (Western) vegetarians and vegans seem to have a bone density that does not significantly differ from omnivores clinically $[22,55]$. In spite of this, the effect of a vegan diet on bone health needs further examination [23].

The associations between bone health-associated nutrients and NEAP found in this study parallel those reported in other studies. Prynne et al. [43], for example, showed that $\mathrm{NEAP}_{\text {Remer-Manz }}$ was positively associated with intake of calcium, phosphorus, sodium and protein and negatively to intake of potassium and vitamin C. These associations were also found in our study in that protein and sodium intake increased, whereas potassium and vitamin $\mathrm{C}$ intake declined with increasing quartiles of NEAP. Again, our results corroborate reports of other researchers. For instance, Gannon et al. [50] observed that protein and phosphorus intakes were significantly associated with increasing quartiles of NEAP, however, there was a marked reduction in vitamin $\mathrm{C}$ intake with increasing quartiles of NEAP.

Since nutrient intake reflects the ingestion of specific foods, we also analyzed associations between food groups and NEAP, and between increasing NEAP quartiles and intake of bread and pastries - a finding consistent with other results [50]. This reflects the sum of sulfuric and organic acid production rates exceeding the bicarbonate production rates of the metabolism of those foods [4]. Furthermore and in accordance with other studies [43, 50], we found a clear and consistent association between decreasing fruit intake with increasing NEAP quartiles. Since fruits and vegetables are foods rich in potassium, which possesses alkaline effects [15], our finding is not surprising.

\section{NEAP of Vegan Diets in the Context of Bone}

Health-Associated Nutrients

As mentioned above, an interpretation of bone-related effects on NEAP should be carried out in the context of the total diet [43]. As our analysis showed, the nutrient intakes of bone health nutrients in vegans met the current DRI recommendations, except for calcium and vitamin D. Especially the vitamin D supply in vegans seems to be a serious problem since foods providing the highest amounts of vitamin D naturally are, except for mushrooms and avocados, all from animal sources. Indeed, there are reports identifying vitamin D deficiency as a problem for vegans [35]. In Finnish vegans, Outila et al. [56] showed that dietary intake of vitamin D was insufficient to maintain serum concentrations of 25-hydroxycholecalciferol (25-OHD) within normal ranges during winter. However, since vitamin D from the diet has only a marginal effect on serum 25-OHD in humans, oral intake of $1 \mu \mathrm{g}$ vitamin D per day increases the 25-OHD level by only 0.66 [57] and $1.96 \mathrm{nmol} / \mathrm{l}$ [58], the vegetarian status is not a significant risk factor for vitamin D deficiency per se $[59,60]$. In vegans, other factors, such as vitamin D supplementation, degree of skin pigmentation, and amount and intensity of sun exposure, have a greater impact on 25-OHD than the diet [56]. Especially solar UVB irradiation is a major determinant for endogenous biosynthesis of vitamin $\mathrm{D}$ and, therefore, the main indicator of 25-OHD serum levels [60]. Accordingly, the marginal vitamin $\mathrm{D}$ content of vegan diets is only relevant if sun exposure is low. In this case, vegans should take vitamin D supplements [35, 61]. With respect to multiple health outcomes, including bone health, a serum 25OHD level of about 75-110 nmol/l (corresponding to oral doses in the range of $45-100 \mu \mathrm{g}$ vitamin $\mathrm{D} /$ day) seems to be optimal [62].

The fact that mean calcium intake in vegans was about $16 \%$ below the DRI recommendations, which is in accordance with other studies [61,63], seems to be problematic with respect to bone health. However, based on the findings of several meta-analyses of observational as well as interventional studies $[64,65]$, the optimal calcium intake for bone health in adults is not well known. Given the fact that the low acidity effect of vegan diets lowers urinary calcium loss, vegans may require less calcium than recommended for omnivore adults. In addition, because higher phosphate intake was associated with decreased urinary calcium and increased calcium retention [66], the phosphate content of vegan diets could result in a lower net need of calcium in vegans.

\section{Limitations of the Study and Conclusion}

As we have stated elsewhere [21], the most important limitation that should be mentioned when examining the results of this study is the use of an FFQ. Actually, the 
overall accuracy of the evaluation of food intake via FFQs has substantial limitations [67] and has therefore been questioned [68]. However, up to now, the FFQ is the standard tool for dietary assessment in all large epidemiological studies, and the results of those studies are still relevant $[69,70]$. Similarly to other studies $[43,44,51]$, we have not assessed bone mineral density or markers of bone turnover. Therefore, it is unknown whether vegans consuming diets with higher acidity compared to those eating more alkaline diets differ with respect to their bone health. A further limitation of our analysis was the fact that we did not measure acid-base status via 24-hour urine collection. Therefore, our estimates of NEAP do not allow us to draw strong conclusions on how vegan diets affect acid-base homeostasis effectively.
In summary, based on our data, it can be hypothesized that vegan diets do not affect acid-base homeostasis. With respect to bone health, further investigation including all dietary components is needed.

\section{Acknowledgments}

The work was supported by grants from the Eden Foundation, Bad Soden, and the Stoll VITA Foundation, Waldshut-Tiengen, Germany.

\section{Disclosure Statement}

None of the authors has any conflict of interest.

\section{References}

1 Sherman HC, Gettler AO: The balance of acid-forming and base-forming elements in foods, and its relation to ammonia metabolism. J Biol Chem 1912;11:323-338.

2 Blatherwick NR: The specific role of foods in relation to the composition of the urine. Arch Intern Med 1914;14:409-450.

$\checkmark 3$ Frassetto LA, Todd KM, Morris RC Jr, et al: Estimation of net endogenous noncarbonic acid production in humans from diet potassium and protein contents. Am J Clin Nutr 1998;68:576-583

4 Remer T, Manz F: Potential renal acid load of foods and its influence on urine $\mathrm{pH}$. J Am Diet Assoc 1995;95:791-797.

$\checkmark 5$ Remer T, Manz F: Estimation of the renal net acid excretion by adults consuming diets containing variable amounts of protein. Am J Clin Nutr 1994;59:1356-1361.

6 Sebastian A, Frassetto LA, Morris RC Jr: The acid-base effects of the contemporary Western diet: an evolutionary perspective; in Alpern RJ, Hebert SC (eds): The Kidney: Physiology and Pathophysiology. Amsterdam, Elsevier, 2007, pp 1621-1644.

-7 Wynn E, Lanham-New SA, Krieg MA, et al: Low estimates of dietary acid load are positively associated with bone ultrasound in women older than 75 years of age with a lifetime fracture. J Nutr 2008;138:1349-1354.

$\checkmark 8$ Welch AA, Bingham SA, Reeve J, et al: More acidic dietary acid-base load is associated with reduced calcaneal broadband ultrasound attenuation in women but not in men: results from the EPIC-Norfolk cohort study. Am J Clin Nutr 2007;85:1134-1141.

$\checkmark 9$ Alexy U, Remer T, Manz F, et al: Long-term protein intake and dietary potential renal acid load are associated with bone modeling and remodeling at the proximal radius in healthy children. Am J Clin Nutr 2005;82: 1107-1114.
10 Macdonald HM, New SA, Fraser WD, et al: Low dietary potassium intakes and high dietary estimates of net endogenous acid production are associated with low bone mineral density in premenopausal women and increased markers of bone resorption in postmenopausal women. Am J Clin Nutr 2005;81:923-933.

11 Meghii S, Morrison MS, Henderson B, et al $\mathrm{pH}$ dependence of bone resorption: mouse calvarial osteoclasts are activated by acidosis. Am J Physiol Endocrinol Metab 2001; 280:E112-E119.

12 Arnett TR, Spowage M: Modulation of the resorptive activity of rat osteoclasts by small changes in extracellular $\mathrm{pH}$ near the physiological range. Bone 1996;18:277-279.

13 New SA, MacDonald HM, Campbell MK, et al: Lower estimates of net endogenous noncarbonic acid production are positively associated with indexes of bone health in premenopausal and perimenopausal women. Am J Clin Nutr 2004;79:131-138.

14 Fenton TR, Eliasziw M, Lyon AW, et al: Me ta-analysis of the quantity of calcium excretion associated with the net acid excretion of the modern diet under the acid-ash diet hypothesis. Am J Clin Nutr 2008;88:11591166.

15 New SA: Intake of fruit and vegetables: implications for bone health. Proc Nutr Soc 2003;62:889-899.

-16 Wynn E, Krieg MA, Aeschlimann JM, et al: Alkaline mineral water lowers bone resorption even in calcium sufficiency: alkaline mineral water and bone metabolism. Bone 2009;44:120-124.

17 Sebastian A, Harris ST, Ottaway JH, et al: Improved mineral balance and skeletal metabolism in postmenopausal women treated with potassium bicarbonate. N Engl J Med 1994;330:1776-1781.
18 Marangella M, Di Stefano M, Casalis S, et al: Effects of potassium citrate supplementation on bone metabolism. Calcif Tissue Int 2004; 74:330-335

19 Haddad EH, Tanzman JS: What do vegetarians in the United States eat? Am J Clin Nutr 2003;78(suppl 3):626S-632S.

$>20$ Waldmann A, Koschizke JW, Leitzmann C, et al: Dietary intakes and lifestyle factors of a vegan population in Germany: results from the German Vegan Study. Eur J Clin Nutr 2003;57:947-955

21 Waldmann A, Ströhle A, Koschizke JW, et al: Overall glycemic index and glycemic load of vegan diets in relation to plasma lipoproteins and triacylglycerols. Ann Nutr Metab 2007; 51:335-344.

22 Ho-Pham LT, Nguyen PL, Le TT, et al: Veganism, bone mineral density, and body composition: a study in Buddhist nuns. Osteoporos Int 2009;20:2087-2093.

23 New SA: Do vegetarians have a normal bone mass? Osteoporos Int 2004;15:679-688.

24 Sanders TA: DHA status of vegetarians. Prostaglandins Leukot Essent Fatty Acids 2009;81:137-141.

25 Elmadfa I, Singer I: Vitamin B-12 and homocysteine status among vegetarians: a global perspective. Am J Clin Nutr 2009;89:1693S1698 S.

26 Tonstad S, Butler T, Yan R, et al: Type of vegetarian diet, body weight, and prevalence of type 2 diabetes. Diabetes Care 2009;32:791796.

27 Chan J, Jaceldo-Siegl K, Fraser GE: Serum 25-hydroxyvitamin D status of vegetarians, partial vegetarians, and nonvegetarians: the Adventist Health Study-2. Am J Clin Nutr 2009;89:1686S-1692S 
28 Robinson-O’Brien R, Perry CL, Wall MM, et al: Adolescent and young adult vegetarianism: better dietary intake and weight outcomes but increased risk of disordered eating behaviors. J Am Diet Assoc 2009; 109:648-655.

-29 Fraser GE: Vegetarian diets: what do we know of their effects on common chronic diseases? Am J Clin Nutr 2009;89:1607S-1612S.

$\checkmark 30$ Yen CE, Yen CH, Huang MC, et al: Dietary intake and nutritional status of vegetarian and omnivorous preschool children and their parents in Taiwan. Nutr Res 2008;28: 430-436.

-31 de Bortoli MC, Cozzolino SM: Zinc and selenium nutritional status in vegetarians. Biol Trace Elem Res 2009;127:228-233.

\32 Karlic H, Schuster D, Varga F, et al: Vegetarian diet affects genes of oxidative metabolism and collagen synthesis. Ann Nutr Metab 2008;53:29-32.

-33 Nakamoto K, Watanabe S, Kudo H, et al: Nutritional characteristics of middle-aged Japanese vegetarians. J Atheroscler Thromb 2008;15:122-129.

>34 Ströhle A, Waldmann A, Wolters M, et al: Vegetarian nutrition: preventive potential and possible risks. Part 1. Plant foods. Wien Klin Wochenschr 2006;118:580-593.

-35 Ströhle A, Waldmann A, Wolters M, et al: Vegetarian nutrition: preventive potential and possible risks. Part 2. Animal foods and recommendations. Wien Klin Wochenschr 2006;118:728-737.

-36 Waldmann A, Dörr B, Koschizke JW, et al: Dietary intake of vitamin $\mathrm{B}_{6}$ and concentration of vitamin $B_{6}$ in blood samples of German vegans. Public Health Nutr 2006;9:779784.

>37 Waldmann A, Koschizke JW, Leitzmann C, et al: German Vegan Study: diet, life-style factors, and cardiovascular risk profile. Ann Nutr Metab 2005;49:366-372.

>38 Waldmann A, Koschizke JW, Leitzmann C, et al: Dietary intakes and blood concentrations of antioxidant vitamins in German vegans. Int J Vitam Nutr Res 2005;75:28-36.

-39 Waldmann A, Koschizke JW, Leitzmann C, et al: Homocysteine and cobalamin status in German vegans. Public Health Nutr 2004;7: 467-472.

40 Waldmann A, Koschizke JW, Leitzmann C, et al: Dietary iron intake and iron status of German female vegans: results of the German Vegan Study. Ann Nutr Metab 2004;48: 103-108.

-41 Krajcovicová-Kudlácková M, Bucková K, Klimes I, et al: Iodine deficiency in vegetarians and vegans. Ann Nutr Metab 2003;47: 183-185.

-42 Ausman LM, Oliver LM, Goldin BR, et al: Estimated net acid excretion inversely correlates with urine $\mathrm{pH}$ in vegans, lacto-ovo vegetarians, and omnivores. J Ren Nutr 2008; 18:456-465.
43 Prynne CJ, Ginty F, Paul AA, et al: Dietary acid-base balance and intake of bone-related nutrients in Cambridge teenagers. Eur J Clin Nutr 2004;58:1462-1471.

44 Chan RS, Woo J, Chan DC, et al: Estimated net endogenous acid production and intake of bone health-related nutrients in Hong Kong Chinese adolescents. Eur J Clin Nutr 2009;63:505-512.

45 Koebnick C, Strassner C, Hoffmann I, et al: Consequences of a long-term raw food diet on body weight and menstruation: results of a questionnaire survey. Ann Nutr Metab 1999;43:69-79.

46 Frassetto LA, Lanham-New SA, Macdonald HM, et al: Standardizing terminology for estimating the diet-dependent net acid load to the metabolic system. J Nutr 2007;137:14911492.

47 Remer T, Dimitriou T, Manz F: Dietary potential renal acid load and renal net acid excretion in healthy, free-living children and adolescents. Am J Clin Nutr 2003;77:12551260.

48 Alexy U, Kersting M, Remer T: Potential renal acid load in the diet of children and adolescents: impact of food groups, age and time trends. Public Health Nutr 2008;11:300-306.

49 Berkemeyer S, Remer T: Anthropometrics provide a better estimate of urinary organic acid anion excretion than a dietary mineral intake-based estimate in children, adolescents, and young adults. J Nutr 2006;136: 1203-1208.

50 Gannon RH, Millward DJ, Brown JE, et al: Estimates of daily net endogenous acid production in the elderly UK population: analysis of the National Diet and Nutrition Survey (NDNS) of British adults aged 65 years and over. Br J Nutr 2008;100:615-623.

51 Deutsche Gesellschaft für Ernährung, Österreichische Gesellschaft für Ernährung, Schweizer Gesellschaft für Ernährungsforschung, Schweizerische Vereinigung für Ernährung. Referenzwerte für die Nährstoffzufuhr. Frankfurt, Umschau/Braus, 2000.

52 Vormann J, Daniel H: The role of nutrition in human acid-base homeostasis. Eur J Nutr 2001;40:187-188.

53 Ströhle A, Hahn A, Sebastian A: Estimation of the diet-dependent net acid load in 229 worldwide historically studied hunter-gatherer societies. Am J Clin Nutr 2010;91:406412.

54 Rylander R, Remer T, Berkemeyer S, et al: Acid-base status affects renal magnesium losses in healthy, elderly persons. J Nutr 2006;136:2374-2377.

55 Lanham-New SA: Is 'vegetarianism' a serious risk factor for osteoporotic fracture? Am J Clin Nutr 2009;90:910-911.
56 Outila TA, Kärkkäinen MU, Seppänen RH, et al: Dietary intake of vitamin D in premenopausal, healthy vegans was insufficient to maintain concentrations of serum 25-hydroxyvitamin D and intact parathyroid hormone within normal ranges during the winter in Finland. J Am Diet Assoc 2000;100: 434-441.

57 Aloia JF, Patel M, Dimaano R, et al: Vitamin $\mathrm{D}$ intake to attain a desired serum 25-hydroxyvitamin D concentration. Am J Clin Nutr 2008;87:1952-1958.

58 Cashman KD, Hill TR, Lucey AJ, et al: Estimation of the dietary requirement for vitamin D in healthy adults. Am J Clin Nutr 2008;88:1535-1542.

59 Nettekoven S, Ströhle A, Trunz B, et al: Effects of antiepileptic drug therapy on vitamin D status and biochemical markers of bone turnover in children with epilepsy. Eur J Pediatr 2008;167:1369-1377.

60 Holick MF: Vitamin D deficiency. N Engl J Med 2007;357:266-281.

-61 Craig WJ, Mangels AR, American Dietetic Association: Position of the American Dietetic Association: vegetarian diets. J Am Diet Assoc 2009;109:1266-1282.

62 Bischoff-Ferrari HA, Shao A, DawsonHughes B, et al: Benefit-risk assessment of vitamin D supplementation. Osteoporos Int 2010;21:1121-1132.

63 Davey GK, Spencer EA, Appleby PN, et al: EPIC-Oxford: lifestyle characteristics and nutrient intakes in a cohort of 33883 meateaters and 31546 non meat-eaters in the UK. Public Health Nutr 2003;6:259-269.

64 Bischoff-Ferrari HA, Dawson-Hughes B, Baron JA, et al: Calcium intake and hip fracture risk in men and women: a meta-analysis of prospective cohort studies and randomized controlled trials. Am J Clin Nutr 2007; 86:1780-1790.

$65 \mathrm{Xu}$ L, McElduff P, D’Este C, et al: Does dietary calcium have a protective effect on bone fractures in women? A meta-analysis of observational studies. Br J Nutr 2004;91:625-634.

-66 Fenton TR, Lyon AW, Eliasziw M, et al: Phosphate decreases urine calcium and increases calcium balance: a meta-analysis of the osteoporosis acid-ash diet hypothesis. Nutr J 2009;8:41.

67 Byers T: Food frequency dietary assessment: how bad is good enough? Am J Epidemiol 2001;154:1087-1088.

68 Kristal AR, Peters U, Potter JD: Is it time to abandon the food frequency questionnaire? Cancer Epidemiol Biomarkers Prev 2005; 14 : 2826-2828.

-69 Kelemen LE: Food frequency questionnaires: not irrelevant yet. Cancer Epidemiol Biomarkers Prev 2006;15:1054.

70 Willett WC, Hu FB: Not the time to abandon the food frequency questionnaire: point. Cancer Epidemiol Biomarkers Prev 2006;15: 1757-1758. 